Provided for non-commercial research and education use. Not for reproduction, distribution or commercial use.

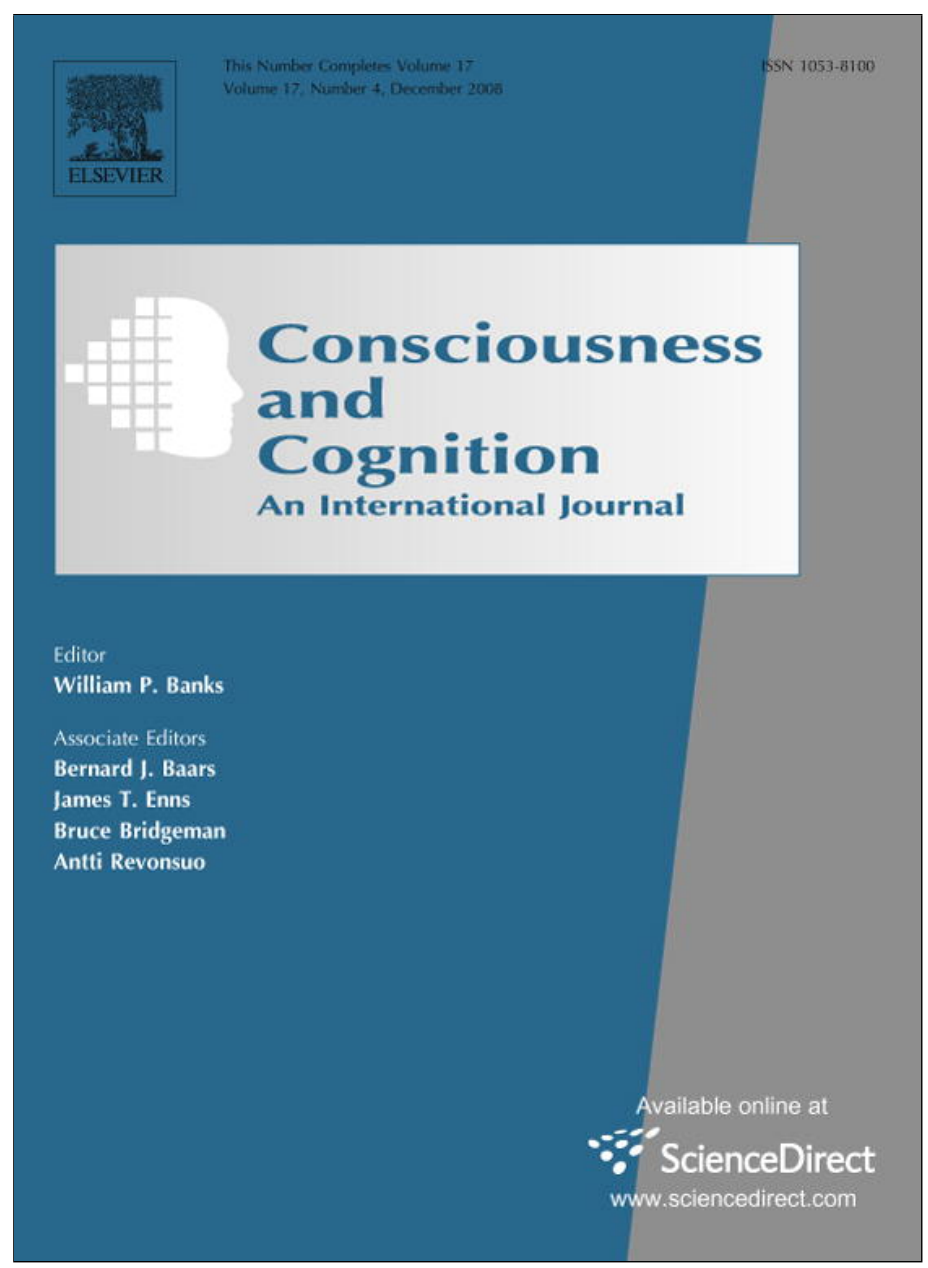

This article appeared in a journal published by Elsevier. The attached copy is furnished to the author for internal non-commercial research and education use, including for instruction at the authors institution and sharing with colleagues.

Other uses, including reproduction and distribution, or selling or licensing copies, or posting to personal, institutional or third party websites are prohibited.

In most cases authors are permitted to post their version of the article (e.g. in Word or Tex form) to their personal website or institutional repository. Authors requiring further information regarding Elsevier's archiving and manuscript policies are encouraged to visit:

http://www.elsevier.com/copyright 
Reply

\title{
The asymmetry between top-down effects and unconscious cognition: Additional issues
}

\author{
Eva Van den Bussche*, Bert Reynvoet \\ Department of Psychology, Faculty of Psychology and Educational Sciences, University of Leuven-Campus Kortrijk, E. Sabbelaan 53, 8500 Kortrijk, Belgium
}

Unconscious cognitive processes are not automatic but flexible in nature and are sensitive to conscious strategic and contextual influences. However, an unconscious stimulus itself cannot modify unconscious processing by exerting top-down control. This double-prediction has been put forward by Dehaene and colleagues within their global neuronal workspace theory (e.g. Dehaene, Changeux, Naccache, Sackur, \& Sergent, 2006; Dehaene \& Naccache, 2001). In a recent study (Van den Bussche, Segers, \& Reynvoet, in press) we affirmed both predictions empirically: we ascertained that a conscious target manipulation (the proportion of Arabic versus number word targets) could be used strategically by the subjects to enhance task performance. Contrarily, the same manipulation applied to the unconscious primes did not induce this top-down effect.

Naccache (in press) remarked that with this asymmetry defined and validated, additional issues are brought to the surface.

A first issue deals with the role of metacognitive processes. Despite the fact that unconscious processes cannot exert a direct top-down influence, the possibility of them exercising an indirect top-down effect should be theoretically viable: an unconscious manipulation could lead to consciously noticeable effects such as response conflict or response time slowing. Once a subject becomes aware of this effect, he/she might be able to use this conscious representation to enhance his/her performance, and thus the unconscious manipulation could exert an indirect effect. Naccache (in press) indicates that this kind of indirect effect is possible, but has not yet been demonstrated. However, we feel that there is already some indirect evidence present in favor of this claim. A first observation that can possibly be interpreted as the effect of an unconscious prime exerting an indirect influence is our own unexpected observation (Van den Bussche et al., in press) that the congruency effect for a certain target notation (Arabic numbers or number words) is more prominent if the proportion of primes in that notation was large as opposed to when the proportion of primes in that notation was small. At first sight, this seems to indicate that an unconscious prime manipulation might exert a direct top-down impact, contrary to the double-prediction. However, when taking a closer look, a more probable explanation lies in the fact that this prime manipulation had an indirect influence. To illustrate this with an example: when subjects receive a digit prime on $75 \%$ of the trials, these digit primes will be unconsciously categorized more often and hence receive an advantage: the brain will learn (unconsciously) to process digits faster. This faster processing of digits will evidently also transfer to digit targets, which will consequently evoke faster responses. At this point subjects might consciously notice this response time facilitation for digit targets and sense that they can enhance their performance by especially focusing on these targets. Consequently, congruency effects will enlarge for trials with digit targets: when subjects receive a congruent digit-digit trial (e.g. 2-1), these trials will receive a double facilitation because the primes do not only lead to the same response as the targets, but the digit targets are also responded to faster. On incongruent digit-digit trials (e.g. 2-9) the digit targets are still responded to faster, but this facilitative effect is neutralized by the opposite responses that are required for prime and target. Taken together, reaction times on congruent trials will be especially fast, while reaction times on incongruent trials will still be slowed down, leading to an enhanced congruency effect for digit targets when $75 \%$ of the presented primes were digits. The same line of reasoning can be applied to number word-digit trials (e.g. two-1) when 75\% number word primes are presented. Thus, completely in line with the suggestion of Naccache, it seems plausible that the unconscious prime manipulation indirectly induced a conscious strategic top-down effect.

An even clearer observation supporting the suggestion of Naccache that an unconscious process can exert an indirect effect, can be found in the large body of data accumulated by Bodner and colleagues (e.g. Bodner \& Dypvik, 2005; Bodner

\footnotetext{
* Corresponding author. Fax: +32 (0) 56246052.

E-mail address: Eva.Vandenbussche@Kuleuven-kortrijk.be (E. Van den Bussche).
} 
\& Masson, 2001, 2003). They observed the phenomenon that masked priming effects are magnified in a block containing a high proportion of trials with valid (e.g. congruent, related or repetition) primes relative to a block containing a high proportion of trials with invalid (e.g. incongruent or unrelated) primes. This prime-validity effect again seems to suggest that subjects are able to strategically use an unconscious prime manipulation directly to improve their performance, which would contradict the claim that unconscious processes are unable to evoke a top-down influence. However, an alternative explanation based on the ASE model (Mozer, Kinoshita, \& Davis, 2004) can be provided for this phenomenon. The ASE model explains the finding that the same item is responded to faster when followed by a series of easy items than when followed by a series of difficult items (e.g. Rastle, Kinoshita, Lupker, \& Coltheart, 2003) and it can also be used to explain the prime-validity effect (Kinoshita, Forster, \& Mozer, 2008). The crucial claim of the ASE model is that the prime-validity effect is not critically dependent on the manipulation of the validity (or usefulness) of the masked primes within a block of trials, but rather on the proportion of easy and difficult trials within a block. More specifically, the prime-validity effect reflects an interaction between item difficulty and difficulty of task environment. The "difficulty" is defined as the rate at which evidence in favor of the correct response accumulates: the evidence for the correct response in an invalid trial builds up more slowly than the evidence for the correct response in a valid trial. What makes the environment easy is irrelevant and therefore not depending on the prime validity: the prime-validity effect is still observed when manipulating the proportion of easy neutral items, even though the proportion of valid primes was constant in the "easy" and "difficult" blocks. Thus, the prime-validity effect does not originate from the proportion of useful versus useless primes in the high and low proportion blocks, but from the proportion of easy versus difficult primes in these blocks. This also indicates that subjects do not strategically use the prime manipulation in a direct way, but rather in an indirect manner. A condition with $20 \%$ congruent (i.e. easy) trials and $80 \%$ incongruent (i.e. difficult) trials could lead to a consciously noticeable response conflict: the subject could get the impression that he/she always tends to give the wrong answer. Once a subject is consciously aware of this, he/she could use this to his/her advantage: he/she could decide to completely ignore the stimulation before and during the prime and focus on the target exclusively. Therefore, in such a condition with only $20 \%$ congruent trials, the priming effects would be strongly reduced as compared to a condition with $80 \%$ congruent prime-target pairs.

These two demonstrations indicate that, while an unconscious manipulation is unlikely to directly influence processing through top-down control, it can indirectly induce a conscious strategic top-down effect. However, this first evidence is indirect and we agree with Naccache (in press) that this issue calls for further direct exploration. Visualizing the underlying neural mechanisms of such observations can be of the utmost importance.

A second issue raised by Naccache (in press) addresses the increasing interest in the interaction between consciousness and cognitive control: for instance, do we need consciousness to inhibit an action? Several studies have shown that unconscious primes can lead to exogenous motor inhibition (e.g. Eimer \& Schlaghecken, 1998). However, it has been claimed that endogenous inhibition (for instance, inhibition which is initiated once a stop or no-go signal has been recognized) can only be initiated with conscious awareness. Eimer and Schlaghecken (2003) for example argued that since endogenous inhibition depends on the conscious detection of task-relevant signals, it is not available when stimuli are presented subliminally. However, very recently (Hughes, 2008, see also Hughes, Velmans, \& De Fockert, 2005) demonstrated in a series of EEG studies that the frontal N2 component, an ERP component associated with inhibition, was modulated by a subliminal prime. Subjects were instructed to press a button following a go stimulus, and to withhold their response following a no-go stimulus. This go/no-go task elicited an early no-go N2 with a frontal topography, which varied as a function of the subliminal primes. This indicates that subjects were successful in unconsciously inhibiting a response. Thus, according to this recent study, endogenous motor inhibition can also be initiated unconsciously. This and other studies (e.g. van Gaal, Ridderinkhof, van den Wildenberg, \& Lamme, 2007) show that we are only at the verge of grasping the dynamics between consciousness and cognitive control. What are the possibilities and limits of cognitive control in unconscious processing? Naccache (in press) justifiably points at the necessity of further exploring this issue. We can even go one step further, and wonder what the role of spatial and/or temporal attention is in this context. We already mentioned that some studies have examined the interaction between consciousness and cognitive control, and others have looked at the interaction between consciousness and attention (e.g. Dehaene et al., 2006). However, how these three fundamental concepts interact with one another remains open for inquiry.

We can conclude that Naccache raised two important additional issues concerning the asymmetry between top-down effects and unconscious cognition raised by our study (Van den Bussche et al., in press). Both have received some attention very recently. However, we fully agree that these issues require further research. Our imagination has now been aroused, erasing the final limiting factor, now let us address these issues!

\section{References}

Bodner, G. A., \& Dypvik, A. T. (2005). Masked priming of number judgements depends on prime validity and task. Memory E Cognition, 33, $29-47$.

Bodner, G. E., \& Masson, M. E. J. (2001). Prime validity affects masked repetition priming: Evidence for an episodic resource account of priming. Journal of Memory \& Language, 45, 616-647.

Bodner, G. E., \& Masson, M. E. J. (2003). Beyond spreading activation: An influence of relatedness proportion on masked semantic priming. Psychonomic Bulletin E' Review, 10, 645-652.

Dehaene, S., Changeux, J. P., Naccache, L., Sackur, J., \& Sergent, C. (2006). Conscious, preconscious, and subliminal processing: A testable taxonomy. Trends in Cognitive Sciences, 10, 204-211.

Dehaene, S., \& Naccache, L. (2001). Towards a cognitive neuroscience of consciousness: Basic evidence and a workspace framework. Cognition, 79, $1-37$. 
Eimer, M., \& Schlaghecken, F. (1998). Effects of masked stimuli on motor activation: Behavioral and electrophysiological evidence. Journal of Experimental Psychology: Human Perception and Performance, 24, 1737-1747.

Eimer, M., \& Schlaghecken, F. (2003). Response facilitation and inhibition in subliminal priming. Biological Psychology, 64, 7-26.

Hughes, G. (2008). Is consciousness required to withhold an impending action? Evidence from event-related brain potentials. Unpublished doctoral dissertation. United Kingdom: University of London.

Hughes, G., Velmans, M., \& De Fockert, J. (2005). Can motor inhibition be initiated unconsciously? Journal of Psychophysiology, 20, 325.

Kinoshita, S., Forster, K. I., \& Mozer, M. C. (2008). Unconscious cognition isn't that smart: Modulation of masked repetition priming effect in the word naming task. Cognition, 107, 623-649.

Mozer, M. C., Kinoshita, S., \& Davis, C. (2004). Control of response initiation: Mechanisms of adaptation to recent experience. Proceedings of the twenty sixth annual conference of the cognitive society. Hillsdale, NJ: Erlbaum Associates.

Naccache, L. (2008). Conscious influences on subliminal cognition exist and are asymmetrical: Validation of a double prediction. Consciousness and Cognition, $17,1359-1360$.

Rastle, K., Kinoshita, S., Lupker, S. J., \& Coltheart, M. (2003). Cross-task strategic effects. Memory E Cognition, 31, 867-876.

Van den Bussche, E., Segers, G., \& Reynvoet, B. (2008). Conscious and unconscious proportion effects in masked priming. Consciousness and Cognition, 17, 1345-1358.

van Gaal, S., Ridderinkhof, K. R., van den Wildenberg, W. P. M., \& Lamme, V. A. F. (2007). Exploring the boundaries of unconscious processing: Response inhibition can be triggered by masked stop-signals. Journal of Vision, 7, 425a. 